\title{
Strength and deformation mechanism of tungsten wires exposed to high temperature annealing: impact of potassium doping
}

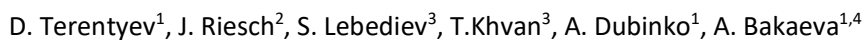

${ }^{1}$ Structural Materials Group, Institute of Nuclear Materials Science, SCK.CEN, Mol, 2400, Belgium

${ }^{2}$ Max-Planck-Institut für Plasmaphysik, 85748 Garching, Germany

${ }^{3}$ V.N. Karazin Kharkiv National University, 4 Svobody Sq., Kharkiv, 61022, Ukraine4

Formatiert: Deutsch (Deutschland)

Abstract

Recent efforts dedicated to the assessment of mechanical properties of tungsten wires, as means for fiber-reinforced composites, have shown that potassium (K) doping in the as-drawn state does not modify the mechanical properties of the wire. High temperature annealing ( $T_{a}$ up to $2300^{\circ} \mathrm{C}$ ) leads to the severe embrittlement of the wire associated with the loss of fracture strength. In this work, we assess the transition behavior of pure and $\mathrm{K}$-doped $\mathrm{W}$ wires exposed to the annealing in the temperature range of $1000-2300^{\circ} \mathrm{C}$ to identify and recommend temperatures suitable for operation and fabrication of the fiber-reinforced composites. The results of mechanical tests performed in the temperature range of $\mathrm{RT}-500^{\circ} \mathrm{C}$ are reported and substantiated by the electron microscopy analysis. Room temperature tests demonstrate that pure $\mathrm{W}$ wires become fully brittle after annealing above $1300^{\circ} \mathrm{C}$, whereas $\mathrm{K}$-doped wires loses ductility above $2100^{\circ} \mathrm{C}$. With raising the test temperature to $300-$ $500^{\circ} \mathrm{C}$, it is found that the strength of pure $\mathrm{W}$ wire reduces by a factor of two at $\mathrm{T}_{\mathrm{a}}=1000^{\circ} \mathrm{C}$ (as compared to non-annealed wire), and goes down to $100 \mathrm{MPa}$ at $\mathrm{T}_{\mathrm{a}}=1900^{\circ} \mathrm{C}$. The $\mathrm{K}$-doping suppresses the reduction of the fracture strength at least up to $\mathrm{T}_{\mathrm{a}}=1900^{\circ} \mathrm{C}$, thus offering a temperature gap of $\sim 600^{\circ} \mathrm{C}$ for the use as reinforcement.

Keywords: Tungsten, fiber, plasticity, recrystallization, potassium doped, annealing, composites.

\section{Introduction}

Drawn tungsten wire originally developed for the illumination industry [1] has been used as reinforcing fiber in various composite concepts [2-4]. In this context, W wire recently got more attention to be used in advanced composites for fusion applications [5]. As a consequence of the drawing process, tungsten wire features a unique microstructure consisting of elongated intertwined grains $[6,7]$. The small grain size perpendicular to the wire axis together with the high dislocation density bestows high ductility (high density of mobile dislocations) [8] and also considerable strength (Hall-Petch strengthening) [9].

In its original application the focus was put on the creep resistance at very high temperature which has been significantly improved by doping pure tungsten wire with small amounts of potassium [10]. 
Further efforts in the research on $\mathrm{W}$ wire have been concentrated for many years in the development of the manufacturing process and high temperature stability of the microstructure. When applied as reinforcement element in composites the performance at lower temperature in general as well as basic mechanical properties like strength or fracture behaviour are becoming of essential importance. Besides the high strength, the ductile deformation is a crucial aspect to ensure durability of the composite under cyclic loads. Several studies were conducted to determine the mechanical properties and ductility at room temperature as well as at elevated temperature. Ability of plastic deformation in tungsten is not only important for the ductility, but also have consequences for the gas diffusion and eventually retention associated with the trapping on dislocations (see refs. [11-13]). Thus, investigation of the capacity of tungsten wires to experience the plastic deformation is important from a number of perspectives.

Recently, a set of $\mathrm{W}$ wires with and without potassium doping was studied in $[14,15]$ by mechanical tests performed up to $600^{\circ} \mathrm{C}$. For the as-drawn wire, the potassium doping practically did not change the response to the mechanical load. The fracture occurred by the elongation and delamination of subgrains (elongated in the direction of wire axis) showing the knife-edge necking fracture typically observed for pure $\mathrm{W}$ wire [16]. Both fracture stress and fracture strain monotonically decreased with increasing test temperature. The necking was essentially localized, and no diffuse necking deformation, usually causing extensive after yield elongation, was found for the wires in the asfabricated condition irrespective of $K$ doping.

The impact of high temperature annealing $\left(T_{a}=2300^{\circ} \mathrm{C}\right)$ on the mechanical properties of the potassiumdoped wire was studied at elevated temperature and followed by detailed microstructural analysis in [15]. The annealing induced severe embrittlement expressed in the strong reduction of the yield and fracture stress. The fracture mechanism was also different, namely: cleavage at $100{ }^{\circ} \mathrm{C}$ and ductile necking above $300{ }^{\circ} \mathrm{C}$. The change of the deformation mechanism and thereby increased elongation was attributed to the onset of the 3D plastic deformation by movement of screw dislocations. The total elongation of the wire before the fracture was much higher as compared to the as-drawn wires. However, despite a positive result with respect to the total elongation, the actual fracture stress is found to be $100 \mathrm{MPa}$ which is very low value to enable reinforcement of the component.

A similar radical change in the deformation behavior is reported for pure tungsten wire treated at elevated temperature [17]. However, the temperature needed to drastically reduce the strength of W wire is significantly lower as compared to doped samples. To understand this difference, one needs to clarify possible microstructural changes associated with the heat treatment and deformation of the material at high temperature.

In pure tungsten wire recrystallization associated with a change in microstructure, i.e. a loss of the socalled Hosford structure as well as a complete removal of the dislocation structure, is reported to occur at $800^{\circ} \mathrm{C}$ [17], as studied by scanning electron microscopy. However, after annealing up to this temperature, the elongated grain structure as well as the good mechanical properties are preserved. In contrast to that, annealing at $1627^{\circ} \mathrm{C}$ leads to the formation of large equiaxed grains and to a severe degradation of the mechanical properties.

The recrystallization of K-doped tungsten is known to be suppressed by the potassium bubbles, which form rows of $\mathrm{K}$ particles at grain boundaries at the onset of the recrystallization thereby inhibiting grain interface movement in radial direction [18]. Thus, the elongated grain structure is retained upon grain 
coarsening until some grains reach the critical size (so called Hillerts criteria [19]) and rapid grain growth is promoted. Therefore, two distinct stages are identified: at first a relatively uniform coarsening sometimes referred to as primary recrystallization (starting in $\mathrm{W}$ at $800^{\circ} \mathrm{C}$ ) followed by a rapid growth of large elongated grains referred to as secondary recrystallization or extensive grain growth (starting in $\mathrm{W}$ at $1900^{\circ} \mathrm{C}$ ) [20].

In this work, we perform a set of parametric mechanical tests at room temperature (RT), 300 and $500^{\circ} \mathrm{C}$ to investigate the fracture stress, uniform elongation, strain hardening and fracture mode of pure and $\mathrm{K}$-doped $\mathrm{W}$ wires annealed in the temperature range of $1000-2300^{\circ} \mathrm{C}$. Thus, the actual transition of the mechanical properties as a function of the annealing temperature going from the dislocation recovery up to the recrystallization has been assessed to reveal limits for the critical reduction of the wire strength.

\section{Experimental details}

Drawn potassium doped (60-75 ppm) and pure tungsten wires, identical to the wires used in [14, 15, 21] were provided by the OSRAM GmbH, Schwabmünchen. The diameter of the wires was measured to be $148.7 \pm 0.2 \mu \mathrm{m}[21]$. Measurements were performed by high resolution optical microscope. The $\mathrm{K}$-doped and pure wires were cut into pieces of $100 \mathrm{~mm}$ and these were annealed at $1000^{\circ} \mathrm{C}, 1300^{\circ} \mathrm{C}$, $1600^{\circ} \mathrm{C}, 1900^{\circ} \mathrm{C}$, and $2100^{\circ} \mathrm{C}$. The highest and lowest annealing temperature was not used for pure and doped $\mathrm{W}$ wire respectively. For the doped $\mathrm{W}$ wire, the changes in the microstructure after annealing at $1000^{\circ} \mathrm{C}$ were considered to be minor, based on the previously performed experiments. While, in the case of pure wire, experience has shown that the annealing at $2100^{\circ} \mathrm{C}$ makes the wire completely brittle such that even clamping procedure may lead to the wire fracture. To perform the annealing, the wire was straightened prior to cutting. The straightened and cut wire pieces were then annealed in a tube furnace under hydrogen atmosphere at Osram $\mathrm{GmbH}$. During this process the samples were placed on a shovel (carbon free) and kept at mentioned temperatures for $30 \mathrm{~min}$.

The ends of the wire pieces (called fibers in the following) were clutched by two parallel mirrorpolished stainless steel plates. The actual gauge section was $30 \mathrm{~mm}$ and the sample holder was equipped with a guide rail to ensure perfect alignment before and during the test. More details about testing procedure can be found in our earlier work [14]. To ensure constant temperature during the test, the gauge section of the sample and inner parts of the holders were placed inside the cylindrical furnace. The temperature of the sample was measured by a thermocouple, connected to a digital voltmeter. Accuracy of the temperature measurement was $\sim 1 \mathrm{~K}$. The samples were tested in air.

The deformation on the sample is applied via the pull rod driven by an electrical gear box, with a maximum load of $0.2 \mathrm{kN}$. A constant displacement loading with a displacement rate of $5 \mu \mathrm{m} / \mathrm{s}$ was applied until fracture. The load, measured by a strain gauge, was registered with a frequency of $0.3 \mathrm{~Hz}$. The initial and final (i.e. after fracture) length of each sample was determined by the horizontal optical comparator with a precision of $1 \mu^{1}$. The relative error on the measurement of the pull rod displacement is $\pm 0.1 \%$ and the absolute error on the stress measurement (considering the crosssection of the fiber to remain constant during the test) is $15 \mathrm{MPa}$.

${ }^{1}$ The fiber ends are placed in the special bed, where one end is abut and the length is measured by optical microscopy. 
To provide information on the morphology of the fracture surface and assist discussion on the deformation mode, the fractured samples were inspected by scanning electron microscopy (SEM, JEOL JSM-6610LV), using a secondary electron (SE) detector and operating conditions were: $20 \mathrm{kV}$ accelerating voltage and 10-15 mm working distance. Each fractured sample was also investigated by the optical microscope Leica to characterize the necking geometry. However, in the following we put emphasis on the mechanical properties, while an in-depth microstructural analysis will be provided in the follow-up work.

\section{Results and discussion}

The test matrix is given in Table 1. At least five valid tests per condition were performed. Here, we provide examples of stress-strain curves and micrographs of few selected fibers, reflecting a typical result obtained for each tested condition. Table 1 thus contains the labels that refer to the ID of the tested fibers whose stress-strain curves and fracture surface images are presented as demonstration of the raw results.

Fig. 1 collects typical stress-strain curves obtained for the both types of fibers tested and annealed at different temperatures. The left column presents the plots for pure tungsten wire and the right one for the doped wire. The test temperature increases from top to down.

Table 1. Test matrix and ID for tested fibers. Samples F8, H10, L8, $\mathbf{0 6}$ are booked for FIB lamella preparation and further TEM microstructural investigation. Samples $\underline{F 2}, \underline{H 4}, \underline{L 2}, \underline{M 1}$ are booked for FIB cutting and subsequent EBSD measurements.

\begin{tabular}{|c|c|c|c|c|}
\hline \multicolumn{2}{|c|}{ Test temperature $\rightarrow$} & & \\
$\downarrow$ Annealing temperature & $T_{t}=R T$ & $T_{t}=300{ }^{\circ} \mathrm{C}$ & $T_{t}=500{ }^{\circ} \mathrm{C}$ \\
\hline$T_{a}=1000{ }^{\circ} \mathrm{C}$ & pure & $\mathrm{D} 1, \mathrm{D} 2$ & $\mathrm{D} 3, \mathrm{D} 4, \mathrm{D} 8$ & $\mathrm{D} 5, \mathrm{D} 6$ \\
\hline \multirow{2}{*}{$T_{a}=1300{ }^{\circ} \mathrm{C}$} & pure & $\mathrm{E} 1, \mathrm{E} 3$ & $\mathrm{E} 8, \mathrm{E} 9, \mathrm{E} 10$ & $\mathrm{E} 4, \mathrm{E} 5, \mathrm{E} 11$ \\
\cline { 2 - 5 } & K doped & $\mathrm{F} 1, \underline{\mathrm{F} 2}$ & $\mathrm{~F} 7, \mathrm{~F} 8, \mathrm{~F} 9$ & $\mathrm{~F} 4, \mathrm{~F} 5, \mathrm{~F} 6, \mathrm{~F} 10$ \\
\hline \multirow{2}{*}{$T_{a}=1600{ }^{\circ} \mathrm{C}$} & pure & $\mathrm{G} 1, \mathrm{G} 2$ & $\mathrm{G} 8, \mathrm{G} 11, \mathrm{G} 12$ & $\mathrm{G} 3, \mathrm{G} 9, \mathrm{G} 13, \mathrm{G} 14$ \\
\cline { 2 - 5 } & K doped & $\mathrm{H} 1, \underline{\mathrm{H} 4}, \mathrm{H} 5$ & $\mathrm{H} 8, \mathrm{H} 9, \mathrm{H} 10, \mathrm{H} 12$ & $\mathrm{H} 6, \mathrm{H} 7, \mathrm{H} 11$ \\
\hline \multirow{2}{*}{$T_{a}=1900{ }^{\circ} \mathrm{C}$} & pure & $\mathrm{K} 9, \mathrm{~K} 13, \mathrm{~K} 14$ & $\mathrm{~K} 2, \mathrm{~K} 7, \mathrm{~K} 10, \mathrm{~K} 11, \mathrm{~K} 15$ & $\mathrm{~K} 3, \mathrm{~K} 6, \mathrm{~K} 12$ \\
\cline { 2 - 5 } & $\mathrm{K}$ doped & $\underline{\mathrm{L} 2}, \mathrm{~L} 3$ & $\mathrm{L8}, \mathrm{L} 9$ & $\mathrm{~L} 5, \mathrm{~L} 7, \mathrm{~L} 10$ \\
\hline$T_{a}=2100{ }^{\circ} \mathrm{C}$ & $\mathrm{K}$ doped & $\mathrm{O} 1, \mathrm{O} 2, \underline{\mathrm{M} 1}, \mathrm{M} 2$ & $\mathbf{0 6}, \mathrm{O} 7, \mathrm{O} 12$ & $\mathrm{O} 8, \mathrm{O}, \mathrm{O} 10, \mathrm{M} 3$ \\
\hline
\end{tabular}



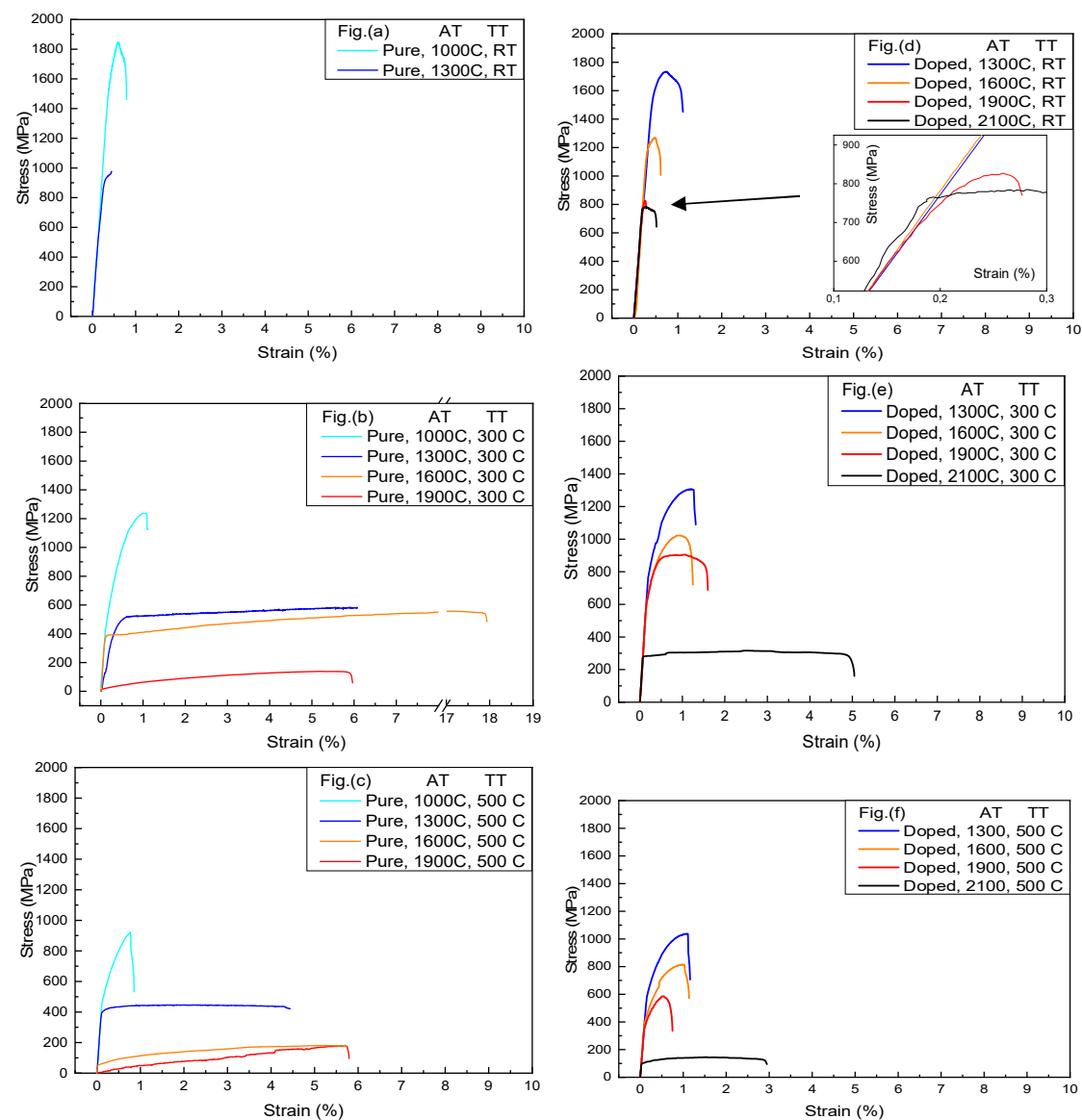

Fig. 1. Stress-strain curves for pure (left coloumn, a-c) and K-doped (right coloumn, d-f) tungsten wires. AT refers to annealing temperature, $T T$ to testing temperature.

It was found that at room temperature, the pure $\mathrm{W}$ wires annealed above $1300^{\circ} \mathrm{C}$ do not reach the yield point and break in the elastic limit, that is why Fig.1(a) contains only data for $T_{a}=1000$ and $1300^{\circ} \mathrm{C}$. As the $T_{t}$ is increased to $300 C^{\circ}$, the yield point and plastic deformation is registered for pure $W$ wires annealed up to $1900^{\circ} \mathrm{C}$. It is however clearly seen from Fig.1(b) and Fig.(c) that the strength of the pure wires annealed up $1900^{\circ} \mathrm{C}$ drops below $200 \mathrm{MPa}$. Fig.1(a-c) also reveals that at elevated temperature, the uniform elongation significantly increases reaching few percent for the wires annealed above $1000^{\circ} \mathrm{C}$. This is accompanied by a decrease in strain hardening, which is dominant in the case of the wire annealed at $1000^{\circ} \mathrm{C}$, and almost not present for wires annealed at higher temperature. This apparently causes the built up of the critical stress intensity sufficient to induce the crack propagation and fracture of the wire. This transition in the plastic behavior should be attributed to microstructural changes as temperature raises from $1000^{\circ} \mathrm{C}$ to $1300^{\circ} \mathrm{C}$ [17]. The loss in strain hardening capacity is probably caused by the reduction of the bulk dislocation density and/or removal of the sub-grains and was reported for similar wire subjected to a longer annealing time ( $3 \mathrm{~h}$ compared to $30 \mathrm{~min}$ ). In that 
study, it was furthermore reported that the grain size is significantly increased accompanied by the loss of the elongated as-drawn grain shape and the formation of equiaxed grains when pure $\mathrm{W}$ wire is subjected to high temperature annealing of $1627^{\circ} \mathrm{C}$. This modification in the grain structure apparently leads to the reduction of the flow stress and certain refinement of the grain interface structure (i.e. formation of rigid grain boundary interface that offers less resistance to the dislocation transmission). Subsequently, the wire yields at a lower level of mechanical load and brittle behaviour as also observed in our study. A similar change in the mechanical properties was observed for thin cold-rolled plate $\mathrm{W}$ (which would be similar to the condition of the here studied as-drawn wires) in the temperature range $1000-1300^{\circ} \mathrm{C}$ [22]. At the same time from Fig.1(b) for $\mathrm{T}_{\mathrm{t}}=300^{\circ} \mathrm{C}$, we can see that the yield stress exhibits two-step reduction after annealing $1000-1300^{\circ} \mathrm{C}$, and after annealing $1600-1900^{\circ} \mathrm{C}$. For the $1900^{\circ} \mathrm{C}$ samples the yield stress is about 20-30 MPa which must correspond to movement of the edge dislocations (the easiest ones to move in BCC W) from the sample surface into the grain boundary free material, although the absence of grain boundaries is still to be confirmed by dedicated microstructural analysis.

The stress-strain curves obtained for the K-doped annealed wire clearly demonstrate the impact of the doping. At room temperature, the annealed wires exhibit limited ductility but still do not break in elastic limit as pure wire does if annealed above $1300^{\circ} \mathrm{C}$. At the same time, one clearly sees the reduction of the yield stress in the same two-step wise form as in pure wire: moderate reduction after annealing up to $1300^{\circ} \mathrm{C}$ and strong reduction after annealing up to $1600^{\circ} \mathrm{C}$. Knowing that potassium stabilizes grain boundaries, one is tempted to ascribe the observed reduction of the yield stress to the removal of the dislocation networks originally introduced by the drawing process. A similar stepwise reduction was observed for the same wire and annealing conditions on another testing system [17]. However, the absolute fracture strength values differ in the two studies. Microstructural investigation is planned to clarify the difference in the fracture stress, therefore the transmission electron microscopy as well as electron back scattering analysis are booked (the corresponding samples are specified in Table 1). Furthermore, Fig.1(d) and Fig.1(f) show that at elevated temperature the most severe drop of the yield stress and fracture stress occurs after annealing up to $2100^{\circ} \mathrm{C}$. This change is likely to be ascribed to the operating of recrystallization which removed at least most of the sub-grains and pre-existing dislocations. By comparing the results for $\mathrm{T}_{\mathrm{t}}=300^{\circ} \mathrm{C}$ (i.e. Fig.1 $\mathrm{b}$ and e), one can conclude that $\mathrm{K}$-doping helps sustaining the mechanical strength and ductility at least up to $\mathrm{T}_{\mathrm{a}}=1900^{\circ} \mathrm{C}$, i.e. which is $300^{\circ} \mathrm{C}$ higher as compared to the $\mathrm{T}_{\mathrm{a}}$ causing the critical reduction of the fracture strength in pure wire. The same conclusion can be made based on the tests perform at $500^{\circ} \mathrm{C}$, but in this case the offset temperature implying positive effect of $\mathrm{K}$-doping is even higher, $\sim 600^{\circ} \mathrm{C}$. By comparison of the strain hardening rate between pure and $\mathrm{K}$-doped wires tested at the same temperature, it is possible to conclude that $\mathrm{K}$-doping stabilizes certain microstructural types of defects which strengthen the material at least up to $1900^{\circ} \mathrm{C}$, while the strain hardening in pure wire reduces abruptly at $\mathrm{T}_{\mathrm{a}}=1300^{\circ} \mathrm{C}$. This observation should be taken as another argument for the fact that $\mathrm{K}$-doping extends the mechanical strength of the wire by about $600^{\circ} \mathrm{C}$ with respect to annealing in the temperature range $1300-1900^{\circ} \mathrm{C}$.

However, the clarification of the above speculations regarding the actual defects responsible for the observed changes requires dedicated transmission electron microscopy and electron back scattering analysis using as-annealed and as-deformed samples, which is out of scope of this contribution but already planned for several samples (see Table 1). 
For each curve the yield strength was calculated as the stress at $0.2 \%$ deformation strain in the elastic regime (i.e. residual deformation was subtracted). It is to be noted, however, that due to the large stiffness a significant amount of plastic deformation is accumulated within the $0.2 \%$ of deformation. Yet, we stick to the classical definition to be able to use the yield strength as a formal value for comparison with bulk material. The fracture stress or ultimate tensile strength (UTS) is taken as the maximum stress registered during the measurement.

Pure W fibers tested at room temperature with annealing temperatures higher than $1300{ }^{\circ} \mathrm{C}$ were broken at elastic region. Apparently, the wire was too brittle to show any plastic deformation at room temperature, hence these results were not added. As we can see, the yield stress and ultimate tensile stress smoothly decrease, as the annealing and test temperature grow up. On the other hand, plastic strain noticeably increases in the boundaries of annealing temperature $1300{ }^{\circ} \mathrm{C}-1900{ }^{\circ} \mathrm{C}$ for pure tungsten and has reversed behavior for K-doped. The uniform elongation for pure and doped tungsten wire is given in Fig. $2 \mathrm{a}$ and $\mathrm{b}$.

Fig. 2 shows that the uniform elongation has a well-pronounced maximum at $T_{t}=300^{\circ} \mathrm{C}$ for the pure wires annealed at $1300 \mathrm{C}$ (and above) and for K-doped wires annealed above $1900^{\circ} \mathrm{C}$. The onset of the plastic deformation at $300^{\circ} \mathrm{C}$ in the recrystallized $\mathrm{K}$-doped $\mathrm{W}$ was discussed in our earlier work [14, 15] and it was attributed to the activation of the motion of screw dislocations, conventionally defining the DBTT in the bulk samples $[23,24]$. Again, it is remarkable that the evident increase of the uniform elongation occurs in $\mathrm{K}$-doped wire only above the $\mathrm{Ta}=1900^{\circ} \mathrm{C}$, while the onset temperature in pure wire is $1300^{\circ} \mathrm{C}$.

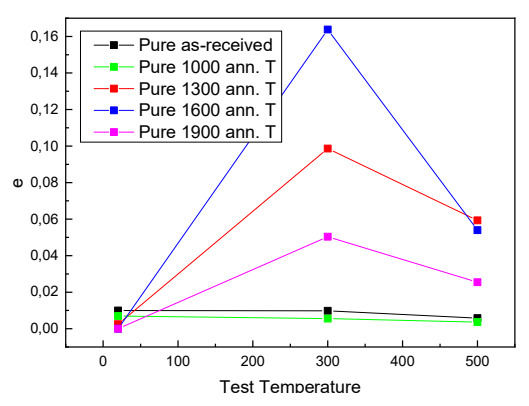

(a)

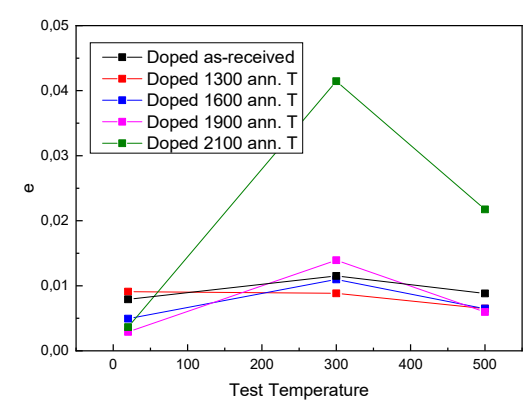

(b)

Fig. 2. Uniform elongation vs Test temperature for (a) pure wires and (b) doped wires.

Figure 3 presents the ultimate tensile strength of K-doped and pure tungsten wires tested at room temperature. One can see that UTS of K-doped wire is distinctly higher (by $\sim 750 \mathrm{MPa}$ ) than for pure wire in the intermediate annealing temperature range $\left(1300^{\circ} \mathrm{C}-1900^{\circ} \mathrm{C}\right)$. 


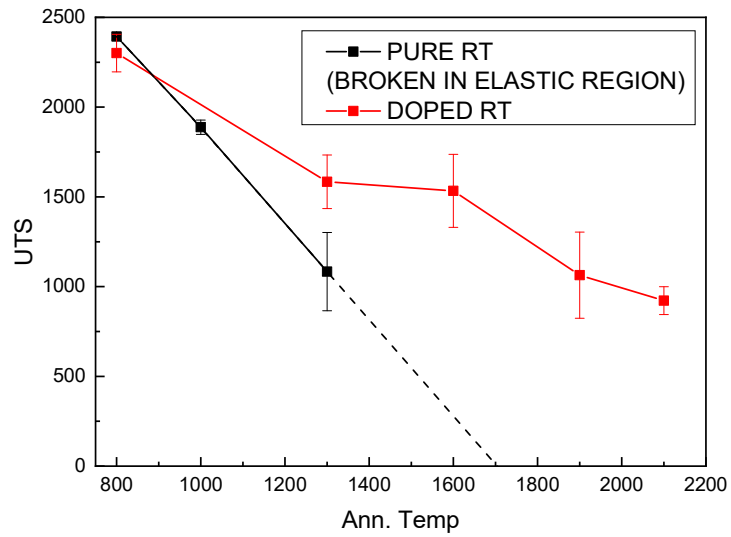

Fig. 3. Ultimate stress vs Annealing Temperature for fibers tested at room temperature

Same effect can be observed for the tests performed at $300{ }^{\circ} \mathrm{C}$ and $500{ }^{\circ} \mathrm{C}$, whose results are presented on Fig. 4 and Fig. 5, respectively.

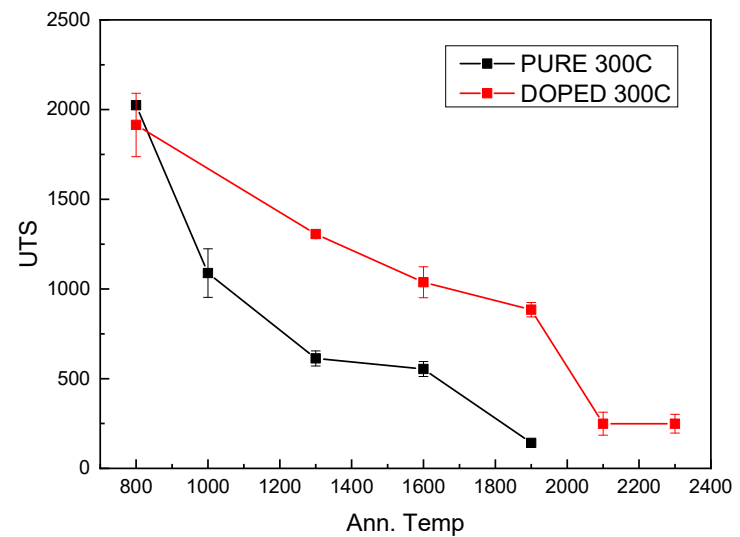

Fig. 4. Ultimate stress vs Annealing Temperature for fibers tested at $300{ }^{\circ} \mathrm{C}$ 


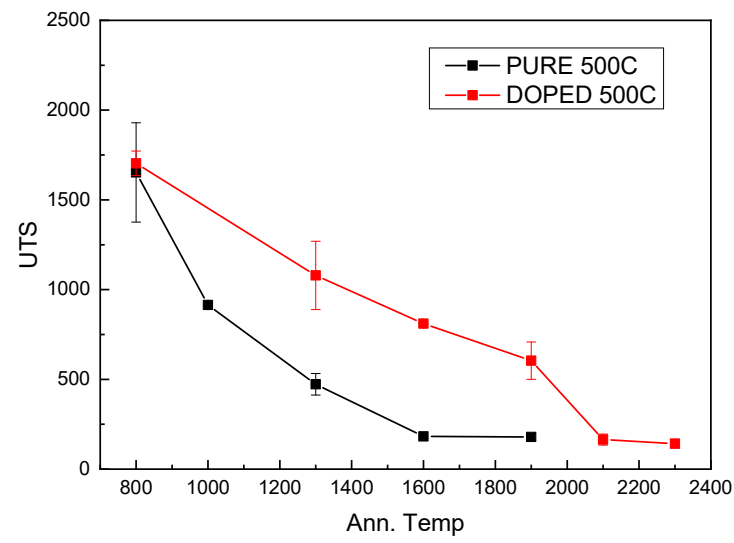

Fig 5. Ultimate stress vs Annealing Temperature for fibers tested at $500{ }^{\circ} \mathrm{C}$

To substantiate the discussion of the results of mechanical tests, we provide the results on the geometry of the fractured ends. The crosshead diameter of the broken pieces was measured by light optical microscopy. Average values for pure and doped tungsten wires tested at room temperature as a function of annealing temperature are presented on Fig. 6.

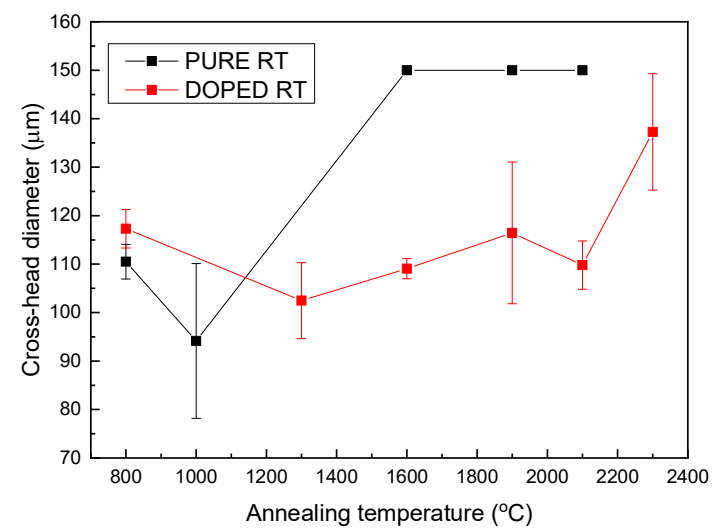

Fig. 6. Crosshead diameters vs Annealing temperature for fibers tested at room temperature

As we can see, the crosshead diameter of pure fiber recovers to its initial value after annealing at $\mathrm{Ta}=1600^{\circ} \mathrm{C}$, which means the fracture of the wire occurs in the elastic region without any contribution from plastic deformation. One can take this temperature as a reference for the annealing condition at which the wire becomes completely brittle. Addition of potassium impurities clearly improves the fiber's plastic properties, so in the case of the doped tungsten wire, some limited plastic deformation is observed even after the annealing up $2300^{\circ} \mathrm{C}$, although the actual diameter wire is getting very close to the non-deformed value. 
While, the detailed microstructural analysis for K-doped wires annealed at $2300 \mathrm{C}$ after the deformation tests was presented in our earlier work [15], here we provide examples of the fracture surface for the lower annealing temperatures.

Each specimen tested in this campaign has been inspected by scanning electron microscopy. Most of surfaces inspected do not have any irregular features and have been already presented in previous publications $[14,15,17,21]$. However, there was a number of observations not reported earlier for which for which we provide the SEM micrographs below.

The fracture surface of the two K-doped wires annealed at $2100^{\circ} \mathrm{C}$ and tested at room temperature are presented in Fig. 7 as OM and SEM taken images. One can see that the specimen had a necking stage during the test, but fracture occurred not in the center of the necking region but next to it. The significance of the local necking region can be appreciated from Fig.7a containing the OM image. We attribute this observation to the fact that the fracture was initiated near the grain boundary which induced the stress concentration in the wire and caused the formation of the necking region. However, the post-necking deformation [25] was not sufficient (due to the low test temperature) and the critical stress has been established next to the grain boundary provoking the crack extension under the action of the dislocation pile-ups [26]. The multiple faceted surface of the fractured wire in Fig.7(b) suggests the presence of the grain boundary interface at the fraction region. The proof of this hypothesis requires detailed analysis using electron backscatter diffraction and transmission electron microscopy, applied locally to the sample to be cut by focus ion beam [27]. Here, we must note that the observation of the fracture next to necking region was seen in the K-doped wires after annealing at $2100^{\circ} \mathrm{C}$ (not below) and in the pure wires after annealing at $1600^{\circ} \mathrm{C}$ (not below). We thus suspect that these are the threshold temperatures for the complete recrystallization to occur with and without potassium doping. It should be also stated that the morphology of surface defects (such as grooves) did not change as a result of the annealing in the whole temperature range explored here. Hence, we attribute the fracture-near-neck phenomenon to the modification of the internal microstructure rather than to the modification of the surface defects.

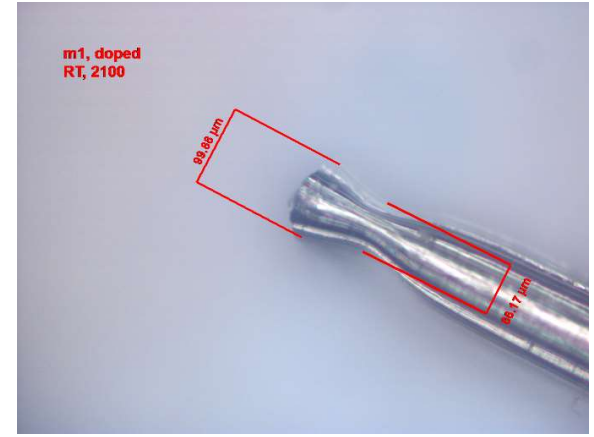

(a)

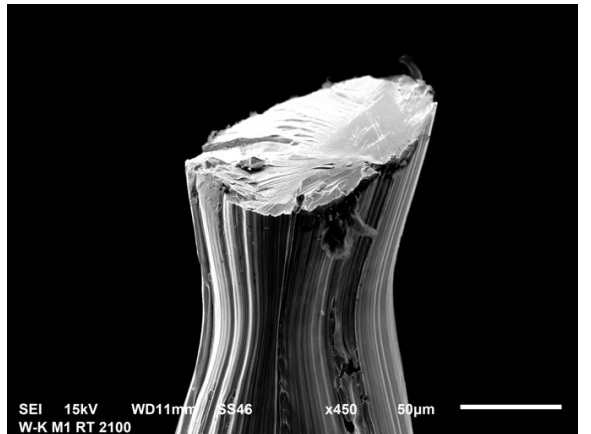

(b)

Fig. $7(a, b)$. OM picture and SEM micrograph of $W$ - $K$ fibers annealed at $2100{ }^{\circ} \mathrm{C}$ and tested at room temperature. 
For the pure $\mathrm{W}$ wires tested at $300^{\circ} \mathrm{C}$ the rotation of the wire was clearly registered. Fig. 8 contains SEM images that show how the pattern of side grooves (originated from the extrusion) twists isolating the main lateral cracks appearing on the fracture surface. In the case of room temperature tests, the grooves remain straight (even in the necking region) thus no torsion-rotation deformation mode was present.

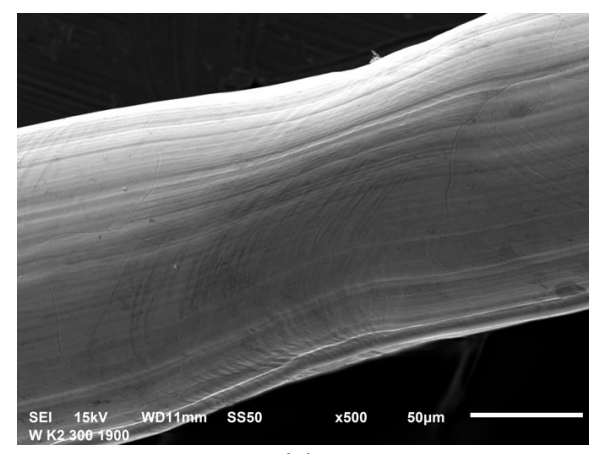

(a)

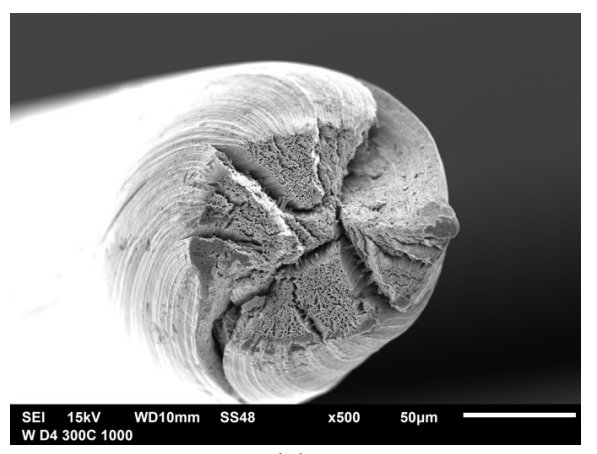

(b)

Fig.8. Pure tungsten fibers annealed at (a) $1900{ }^{\circ} \mathrm{C}$ and (b) $1000^{\circ} \mathrm{C}$ and tested at $300{ }^{\circ} \mathrm{C}$.

Finally, for both pure and $\mathrm{K}$-doped $\mathrm{W}$ wires tested at $300^{\circ} \mathrm{C}$ and $500^{\circ} \mathrm{C}$ for many wires we could register the occurrence of multiple necking regions (see Figs.9). The formation of the chain of necking regions can be attributed to the repeatable diffuse necking as was observed for the corresponding wires on the stress-strain curves. This observation points to the high complexity of the analysis and extraction of the true stress-strain behavior of such wires. In the case of the fully recrystallized wire (as studied earlier in [15]), mostly a single necking region was identified and even then there can be a considerable uncertainty with respect to the restoration of the true characteristics.

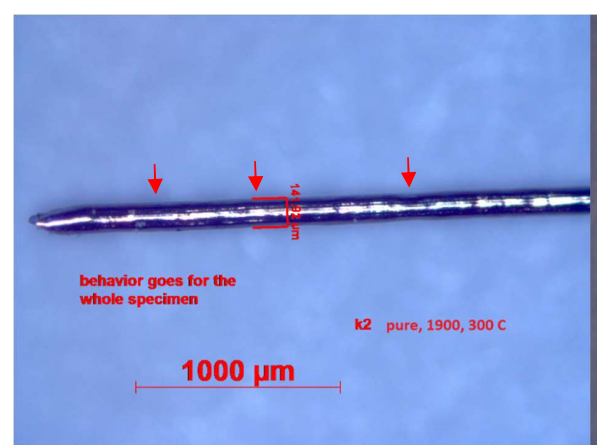

(a)

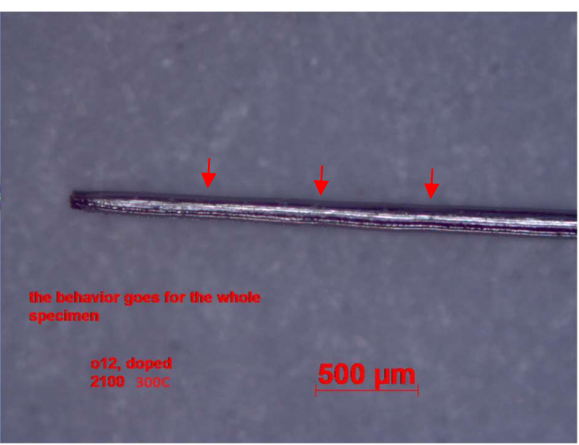

(b) 


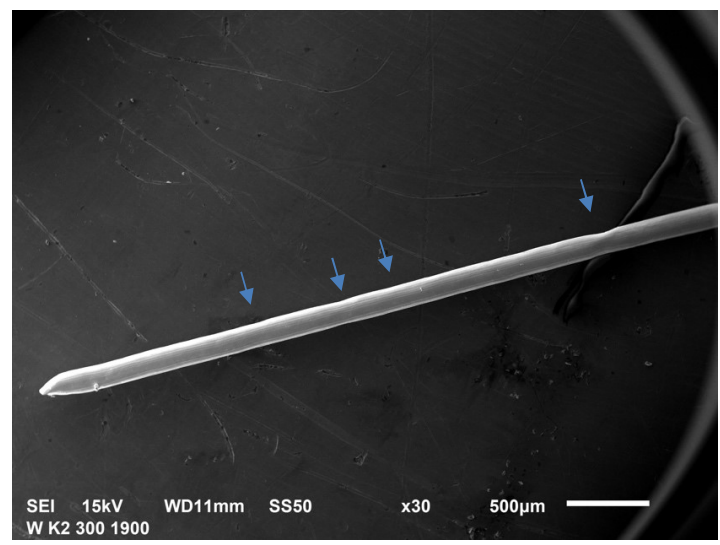

(c)

Fig.9. Pure tungsten fiber annealed at (a,c) $1900{ }^{\circ} \mathrm{C}$ and (b) $2100{ }^{\circ} \mathrm{C}$ and tested at $300{ }^{\circ} \mathrm{C}$. Arrows indicate exemplarily locations of diffuse necking.

\section{Summary and conclusive remarks}

To summarize, in this work we have assessed the tensile mechanical properties of pure and K-doped tungsten wires being exposed to high temperature annealing in the range of $1000-2300^{\circ} \mathrm{C}$. The mechanical tests were performed at room temperature, 300 and $500^{\circ} \mathrm{C}$. The primary purpose of the study was a clarification of the impact of the annealing and presence of potassium on the strength of the wire and its ability for plastic deformation.

In the case of pure $\mathrm{W}$ wire it is found that:

- the annealing at $1600^{\circ} \mathrm{C}$ and above causes complete embrittlement of the wire at room temperature, which is to be associated with the removal of the structural defects (dislocations and grain boundary interfaces) originally present in the drawn wire. Annealing up to $1300^{\circ} \mathrm{C}$ results in the progressive reduction of the ultimate tensile strength (down to $1 \mathrm{GPa}$ ), but the wire still exhibits limited plastic deformation at room temperature.

- tensile tests performed at the elevated temperature demonstrate that the annealing at $1600^{\circ} \mathrm{C}$ and above results in the huge reduction of the ultimate tensile strength (down to $200 \mathrm{MPa}$ ), while the wires exhibit large plastic deformation prior to the fracture.

- following the above observations, it is possible to conclude that annealing above $1600^{\circ} \mathrm{C}$ causes major removal of the microstructural defects which strengthen the wire (in as-fabricated state), and at 
elevated temperature such heavily annealed wires experience large plastic deformation without considerable work-hardening, and therefore the fracture stress remains rather low.

In the case of K-doped wires, the results of mechanical tests have demonstrated that:

- limited plastic deformation at room temperature is observed on the wires annealed up to $2100^{\circ} \mathrm{C}$. This means that no complete recovery of the as-fabricated microstructure was accomplished at $2100^{\circ} \mathrm{C}$. However, the ultimate tensile strength does go down progressively from about $2.3 \mathrm{GPa}$ to 0.8 $\mathrm{GPa}$ (for $2100^{\circ} \mathrm{C}$ annealed wire).

- the tests performed at the elevated temperature, revealed that the mechanical response changes as the annealing temperature increases from 1900 to $2100^{\circ} \mathrm{C}$. The yield stress goes below $300 \mathrm{MPa}$ and strain hardening is practically absent. This points to the change of the deformation mechanism associated with the modification of the wire's microstructure. Apparently, annealing above $1900^{\circ} \mathrm{C}$ completes the removal of dislocations and low-angle grain boundaries, while some fraction of high angle grain boundaries (assumed to be more stable with respect to annealing) remains.

By comparing the results of mechanical tests for pure and K-doped samples, one can state the following regarding the impact of the potassium doping:

- For the wires annealed at $1300^{\circ} \mathrm{C}$ and above, K-doping clearly retards the strong reduction of the ultimate tensile strength, otherwise observed in pure wire.

- The above-noted positive effect preserves up to the annealing temperature of $1900^{\circ} \mathrm{C}$. Above this annealing temperature, the plastic deformation mechanism changes and the ultimate tensile strength of the wire goes below $300 \mathrm{MPa}$ at elevated temperature.

In addition to the mechanical data, preliminary microstructural inspection has demonstrated a number of new features which were not reported earlier when only as-fabricated and $2300^{\circ} \mathrm{C}$ annealed wires were studied, namely:

- The K-doped wires exposed to $2100^{\circ} \mathrm{C}$ annealing exhibit the local-necking near the fracture region. This must be attributed to the presence of some microstructural defects inside the wire, which induced local stress concentration. Thus, it supports our above conclusion that $\mathrm{K}$-doping up to $2100^{\circ} \mathrm{C}$ still suppresses complete recrystallization of the fiber into single-crystal like wire.

- The pure $\mathrm{W}$ wires, tested at elevated temperature, appear to have fracture surface showing considerable torsion occurred in the wire prior the fracture. This was not reported earlier, while it proves that the local rotation in the necking region also takes place. This rotation must be associated with the plastic deformation promoted by dislocation slip.

- Finally, for the wires (both K-doped and pure ones) tested at elevated temperature where high elongation was observed, the inspection by optical microscopy has revealed multiple necking regions. This implies further complexity in the restoration of the actual true stress - true strain characteristic. 


\section{Acknowledgement}

This work has been carried out within the framework of the EUROfusion Consortium and has received funding from the Euratom research and training programme 2014-2018 under grant agreement No 633053. The views and opinions expressed herein do not necessarily reflect those of the European Commission. The work was partially supported by FOD grant of Belgium Government. The authors want to acknowledge support by Osram $\mathrm{GmbH}$, Schwabmünchen, Germany for providing the tungsten wire and performing the annealing.

[1] P. Schade, 100 years of doped tungsten wire, Int J Refract Met H 28(6) (2010) 648-660.

[2] D.W. Petrasek, D.L. Mcdanels, L.J. Westfall, J.R. Stephens, Fiber-Reinforced Superalloy Composites Provide an Added Performance Edge, Met Prog 130(2) (1986) 27-31.

[3] J. Hill, F. Banta, Characterization of wire-wound tungsten composite, Technical Report AFML-TR71-245 United Technology Centre (1972).

[4] D.L. Mcdanels, Tungsten Fiber Reinforced Copper Matrix Composites, NASA Technical Paper 2924 URL: http://www.dtic.mil/cgi-bin/GetTRDoc?AD=ADA309283 (1989).

[5] C. Linsmeier, M. Rieth, J. Aktaa, T. Chikada, A. Hoffmann, J. Hoffmann, A. Houben, H. Kurishita, X. Jin, M. Li, A. Litnovsky, S. Matsuo, A. von Muller, V. Nikolic, T. Palacios, R. Pippan, D. Qu, J. Reiser, J. Riesch, T. Shikama, R. Stieglitz, T. Weber, S. Wurster, J.H. You, Z. Zhou, Development of advanced high heat flux and plasma-facing materials, Nuclear Fusion 57(9) (2017).

[6] E.S. Meieran, D.A. Thomas, Structure of drawn and annealed tungsten wire, Transactions of the Metallurgical Society of AIME 233 (1965) 937-943.

[7] A. Barna, I. Gaal, O. Geszti-Herkner, G. Radnoczi, L. Uray, FIBRE STRUCTURE OF K-Si-Al DOPED TUNGSTEN WIRES, High Temperatures - High Pressures 10(2) (1978) 197-205.

[8] J. Riesch, J. Almanstotter, J.W. Coenen, M. Fuhr, H. Gietl, Y. Han, T. Hoschen, C. Linsmeier, N. Travitzky, P. Zhao, R. Neu, Properties of drawn W wire used as high performance fibre in tungsten fibre-reinforced tungsten composite, 37th Riso International Symposium on Materials Science 139 (2016).

[9] J. Riesch, A. Feichtmayer, M. Fuhr, J. Almanstötter, J.W. Coenen, H. Gietl, T. Höschen, C. Linsmeier, R. Neu, Tensile behaviour of drawn tungsten wire used in tungsten fibre-reinforced tungsten composites, Physica Scripta 2017 (2017) 014032.

[10] C.L. Briant, B.P. Bewlay, The Coolidge Process for Making Tungsten Ductile - the Foundation of Incandescent Lighting, Mrs Bull 20(8) (1995) 67-73.

[11] D. Terentyev, V. Dubinko, A. Bakaev, Y. Zayachuk, W. Van Renterghem, P. Grigorev, Dislocations mediate hydrogen retention in tungsten, Nuclear Fusion 54 (2014) 042004.

[12] D. Terentyev, G. De Temmerman, T.W. Morgan, Y. Zayachuk, K. Lambrinou, B. Minov, A.

Dubinko, K. Bystrov, G. Van Oost, Effect of plastic deformation on deuterium retention and release in tungsten, J Appl Phys 117(8) (2015).

[13] D. Terentyev, G. De Temmerman, B. Minov, Y. Zayachuk, K. Lambrinou, T.W. Morgan, A. Dubinko, K. Bystrov, G. Van Oost, Synergy of plastic deformation and gas retention in tungsten, Nuclear Fusion 55(1) (2015) 013007.

[14] D. Terentyev, J. Riesch, S. Lebedev, A. Bakaeva, J.W. Coenen, Mechanical properties of asfabricated and $2300^{\circ} \mathrm{C}$ annealed tungsten wire tested up to $600^{\circ} \mathrm{C}$, Int J Refract Met H 66 (2017) 127-134.

[15] D. Terentyev, J. Riesch, S. Lebediev, T. Khvan, A. Zinovev, M. Rasiński, A. Dubinko, J.W. Coenen, Plastic deformation of recrystallized tungsten-potassium wires: constitutive deformation law in the temperature range $22-600^{\circ} \mathrm{C}$, Int J Refract Met H 66 (2018) 127-134. 
[16] S. Leber, J. Tavernelli, D.D. White, R.F. Hehemann, Fracture Modes in Tungsten Wire, J LessCommon Met 48(1) (1976) 119-133.

[17] P. Zhao, J. Riesch, T. Hoschen, J. Almanstotter, M. Balden, J.W. Coenen, R. Himml, W. Pantleon, U. von Toussaint, R. Neu, Microstructure, mechanical behaviour and fracture of pure tungsten wire after different heat treatments, Int J Refract Met H 68 (2017) 29-40.

[18] D.B. Snow, The recrystallization of non-sag tungsten wire The Metallurgy of Doped/Non-Sag Tungsten Elsevier Applied Science, New York, 1989.

[19] M. Hillert, On the theory of normal and abnormal grain growth, Acta Metall. 13 (1965) 783-794.

[20] D.B. Snow, Recrystallization of Heavily-Drawn Doped Tungsten Wire, Metall Trans A 7(6) (1976)

783-794.

[21] J. Riesch, Y. Han, J. Almanstotter, J.W. Coenen, T. Hoschen, B. Jasper, P. Zhao, C. Linsmeier, R. Neu, Development of tungsten fibre-reinforced tungsten composites towards their use in DEMOpotassium doped tungsten wire, Physica Scripta T167 (2016).

[22] J. Reiser, M. Rieth, B. Dafferner, A. Hoffmann, X.O. Yi, D.E.J. Armstrong, Tungsten foil laminate for structural divertor applications - Analyses and characterisation of tungsten foil, Journal of Nuclear Materials 424(1-3) (2012) 197-203.

[23] A. Giannattasio, M. Tanaka, T.D. Joseph, S.G. Roberts, An empirical correlation between temperature and activation energy for brittle-to-ductile transitions in single-phase materials, Physica Scripta T128 (2007) 87-90.

[24] A. Giannattasio, Z. Yao, E. Tarleton, S.G. Roberts, Brittle-ductile transitions in polycrystalline tungsten, Philosophical Magazine 90(30) (2010) 3947-3959.

[25] A. Zinovev, D. Terentyev, A. Dubinko, L. Delannay, Constitutive law for thermally-activated plasticity of recrystallized tungsten, Journal of Nuclear Materials 496 (2017) 325-332.

[26] D. Terentyev, A. Bakaev, A. Serra, F. Pavia, K.L. Baker, N. Anento, Grain boundary mediated plasticity: The role of grain boundary atomic structure and thermal activation, Scripta Materialia 145 (2018) 1-4.

[27] W. Van Renterghem, A. Dubinko, A. Bakaeva, D. Terentyev, TEM investigation of the effect of He-seeding on plasma induced defects in tungsten, Journal of Nuclear Materials 508 (2018) 74-81. 